\title{
The effects of flicker on the perception of figure and ground
}

\author{
EVA WONG \\ University of Denver, Denver, Colorado \\ and \\ NAOMI WEISSTEIN \\ State University of New York at Buffalo, Amherst, New York
}

\begin{abstract}
Flickering areas of the visual field are perceived predominantly as backgrounds and the adjacent nonflickering areas are seen as figures. The effect of flicker on anchoring a region as ground is optimal within a limited range of temporal frequencies. Within the temporal frequencies used in the present experiments, the effect was greatest at 6.3 and $8.3 \mathrm{~Hz}$. At these flicker rates the flickering regions were seen as ground over $75 \%$ of the time, whereas at 1.4 and $12.5 \mathrm{~Hz}$ the flickering regions were seen as ground less than $60 \%$ of the time. The average temporal luminance of the flickering and nonflickering areas was kept equal, so the figure-ground perception we found is not due to any luminance differences between the two regions. The flickering areas seen as ground were also perceived to lie on a depth plane behind the nonflickering figure regions. The amount of perceived depth separation increased as the regions became more perceptually anchored. The temporal tuning function of flicker-induced ground appears to be similar to those of visual pathways most sensitive to high temporal frequency.
\end{abstract}

How objects and entities are segregated from their backgrounds has fascinated psychologists for a long time. Our mobility in the environment is dependent on our ability to distinguish objects from backgrounds so that we can interact efficiently with things in the world. In this paper, we report a number of experiments that show that temporal frequency can be a powerful determinant of figureground perception.

The earliest attempts at studying figure-ground perception were primarily concerned with describing the visual impressions of figure and ground regions of the visual field (Koffka, 1935; Rubin, 1921/1958). The figure was described as a "richer, more differentiated structure than the same field experienced as ground" (Rubin, $1921 / 1958$, p. 197). The contours that were shared boundaries between figure and ground appeared to "belong" to figure, while the ground appeared to extend behind the figure as a formless region. Other investigators looked at the stimulus arrangements determining figure-ground perception and found that size, hue, contrast, region orientation, and symmetry are prominent factors (Bahnsen, 1928; Goldhammer, 1934; Graham, 1929; Harrower, 1936; Künnapas, 1957; Oyama \& Sasamoto, 1957; Oyama \& Torri, 1955; Oyama, 1960). Not only were stimulus arrangements found to affect figure-ground organization, but the perceptual properties of figure and ground were also found to be different. Regions change color, contrast, and brightness as they undergo figure-

Eva Wong's address is: Department of Psychology, University of Denver, University Park, Denver, CO 80208-0204. ground shifts, without any changes in the physical stimuli (Coren, 1969; Festinger, Coren, \& Rivers, 1970; Frank, 1923). More recently, an approach to the study of figureground perception has been to examine its relationship to other functions of visual processing. Julesz (1971) related figure-ground organization to motion and depth cues. Clusters of dots moving in the same direction segregated from a field of stationary dots to form a figure (Frost \& Nakayama, 1983; Julesz, 1971). If two fields of dots moved at different rates, the area with the faster moving dots was more dominantly seen as figure. Moreover, if the slower moving dots became hidden when they moved into the region of the faster moving dots, then the powerful depth cue of interposition made the faster moving cluster appear in depth to be in front of the slowermoving background. Stereopsis was also found to determine figure-ground organization. Areas of the visual field whose disparity was manipulated so that they appeared to be behind other regions were seldom seen as figures (Julesz, 1971). These demonstrations showed that the early visual processes of stereopsis and motion processing can affect figure-ground segregation.

We found another early visual process, that of temporal frequency, to be a powerful determinant of figure-ground organization (Wong \& Weisstein, 1984b). Flickering regions of the visual field, especially in ambiguous figures, were predominantly seen as backgrounds, and nonflickering areas were predominantly seen as figures. We called this the flicker-induced ground effect. We also found that the regions perceived as figures were seen as being in front of the regions perceived as backgrounds. 
In this paper we report four experiments in which we examined the effects of flicker on the perception of figure and ground.

\section{EXPERIMENT 1A}

In this experiment we examined the effect of temporal frequency or flicker on figure-ground organization in the Rubin goblet/faces reversible picture.

\section{Method}

Subjects. Twenty subjects, all undergraduates, participated in this experiment. All had 20/20 vision.

Stimuli and Apparatus. The display is shown in Figure 1. Stimuli were generated by a PDP-11 computer with a GT-40 graphics processor and displayed on a CRT with a p-15 phosphor. A $3.2^{\circ} \times 3.2^{\circ}$ region of the CRT screen was filled with random dots. This enclosed region was divided into three areas that corresponded to the three segments of Rubin's faces/goblet reversible picture. In this experiment, the outline of the Rubin picture was drawn in. The three segments of the Rubin picture were matched as closely as possible in area. Each area was filled with 75 dots. Each region with its dots was generated as a subpicture. The subpicture is a list of screen coordinates of all the dots contained in a region, for example, the goblet region. Subpictures are created off-screen, normally as part of the start-up routine at the beginning of an experiment. When the region, with its dots, is displayed during a trial, the display processor is concerned only with "turning on" the subpicture, that is, with the intensification of the dots. The coordinates have already been computed and plotted. This eliminates extra instructional and computational time on the part of the host computer and the display processor. The average luminance of the flickering and nonflickering regions was kept equal. The luminance of the nonflickering region was measured by a photometer. The luminance of the flickering region was set so that the mean temporal luminance [(maximum + minimum)/2] equaled the luminance of the nonflickering region. Luminance was set low so that phosphor persistence was reduced to a minimum during flicker. The rise time of the phosphor and the time required for the display processor to intensify all the dots were checked with an oscilloscope and were found to follow a square-wave function. This en-

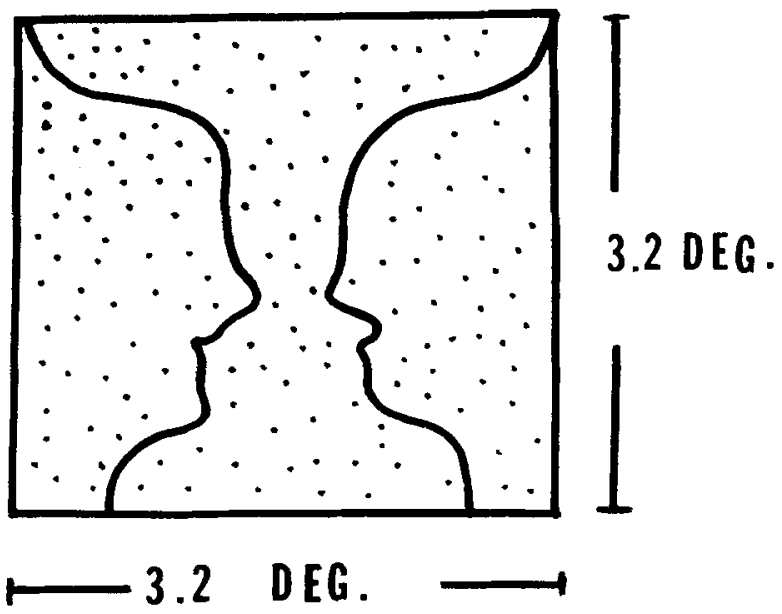

Figure 1. Rubin's reversible faces/goblet picture. This display was used in Experiments 1A and 1B. The three regions of the figure were defined by solid contours in Experiment $1 A$ but not in Experiment 1B. sured that instantaneous on-off was approximated as closely as possible.

Procedure. Before the experiment was run, the subjects viewed the display with none of the regions flickering. They pressed a switch when they perceived a goblet and released the switch when they perceived faces. This control condition provided information about any tendencies for subjects to perceive a particular organization without flicker.

There were two conditions in the experiment. In one condition, the central area of the Rubin picture flickered while the flanking areas remained static. In the other condition, the flanking areas of the Rubin picture flickered while the central area remained static. In each of these conditions, there were four flicker rates: $1.4,6.3$, 8.3 , and $12.5 \mathrm{~Hz}$. Depth of modulation was always set at $100 \%$ and square-wave flicker was used throughout. The square outline was always present on the screen so that the subject knew where the display would appear. Presentation of the display condition and selection of flicker rate were totally randomized. The two flicker display conditions, each with four temporal frequencies, and the control condition generated nine stimulus conditions. Each stimulus was presented 10 times during the experiment, making a total of 90 trials for each subject.

In a typical trial, the subject pressed a computer key when ready. Immediately, the display appeared and the selected regions flickered at one of the temporal frequencies. The display was exposed for $30 \mathrm{sec}$. During the trial, the subject held a switch, which he/she depressed every time the goblet was perceived and released when faces were perceived. The positions of the switch recorded during the trial indicated the percentage of time a particular region was seen as figure. At the end of each trial, the subject indicated whether the flickering region(s) was in front of or behind the nonflickering regions, and which region(s) appeared brighter. (In previous experiments on flicker and region segregation [Wong \& Weisstein, 1984a], we found that when flickering and nonflickering areas were matched for luminance, the flickering regions always appeared brighter than the nonflickering regions.) $A$ horizontal line appeared at the bottom of the screen and the subject adjusted its length to match the amount of perceived depth segregation between the flickering and nonflickering regions.

\section{Results}

First, subjects did not exhibit any pronounced preference for seeing any particular segment as figure when none of the areas flickered. Neither goblet nor faces were perceived more than $58 \%$ of the time.

Second, when the flanking regions of the Rubin picture flickered, the central region was perceived predominantly as a figure; that is, a goblet was seen. When the central region of the Rubin picture flickered, the flanking regions were perceived predominantly as figure; that is, faces were seen. The flickering background regions were also primarily seen as lying behind the static figural regions. These visual impressions are illustrated in Figure 2. The most pronounced effect of flicker on anchoring a region as background was at 6.3 and $8.3 \mathrm{~Hz}$. The effect diminished as temporal frequency increased or decreased, suggesting a tuning function. Figure 3 shows the percentage of time a flickering region was seen as figure versus the percentage of time a nonflickering region was seen as figure. Since there were no significant differences between data from the condition in which the center flickered and those from the condition in which the flanks flickered, the data were collapsed together. 
Flickering

Flanking Regions

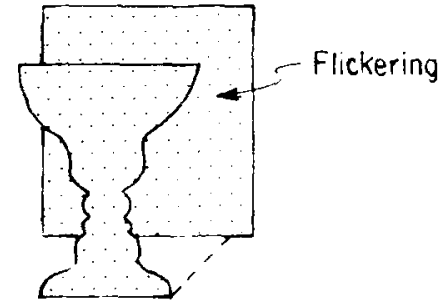

Flickering Central Region

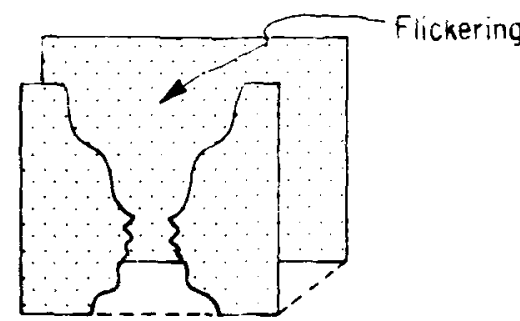

Figure 2. Visual impression of the faces/goblet reversible picture when the central regions flickered and when the flanking regions flickered.

Figure 3 shows the percentage of time a flickering region was seen as figure and the percentage of time a nonflickering region was seen as figure when the neighboring regions were flickered. At 6.3 and $8.3 \mathrm{~Hz}$ the flickering regions were rarely seen as figure (less than $25 \%$ of the time); that is, they were perceived as backgrounds over $75 \%$ of the time. When the same regions were presented steadily while the neighboring areas flickered, they were seen as figures over $80 \%$ of the time. At 1.4 and $12.5 \mathrm{~Hz}$, the effect of flicker on anchoring a particular region as ground was less pronounced. No particular region was seen as figure for a significant percentage of time. When the regions flickered, they were seen as figures about $36 \%$ of the time and as ground about $74 \%$ of the time. A oneway ANOVA (repeated measures) was performed on the response time in which the flickering region was perceived as ground at four temporal frequencies $(1.4,6.3,8.3$, and $12.5 \mathrm{~Hz})$. The main effect was significant $[F(3,57)=$ $5.66, p<.005]$. In general, nonflickering regions were seen predominantly as figures. A post hoc comparison between levels was also performed to determine the contribution of each of the four temporal frequencies. Means for 6.3 and $8.3 \mathrm{~Hz}$ were significantly different from those for the other temporal frequencies. This reflects the enhanced effects of these two flicker rates in anchoring a region as background. No significant differences were found between 6.3 and $8.3 \mathrm{~Hz}$ or between 1.4 and $12.5 \mathrm{~Hz}$.

Third, we examined the amount of perceived depth separation between the flickering and nonflickering regions at each of the flicker rates. No subject perceived the flickering areas to be in front of the nonflickering regions for any flicker rate (binomial, $p<.001$ ). All of the subjects perceived the flickering and nonflickering areas to be segregated into definite regions, regardless of amount of depth perceived. Perceived depth between the flickering and nonflickering regions was greatest at 6.3 and $8.3 \mathrm{~Hz}$. This is consistent with the findings of Wong and Weisstein (1984a, 1985) on flicker-induced depth effects. Table 1 shows the amount of depth perceived and the percentage of time the flickering regions were seen as ground at the four temporal frequencies.

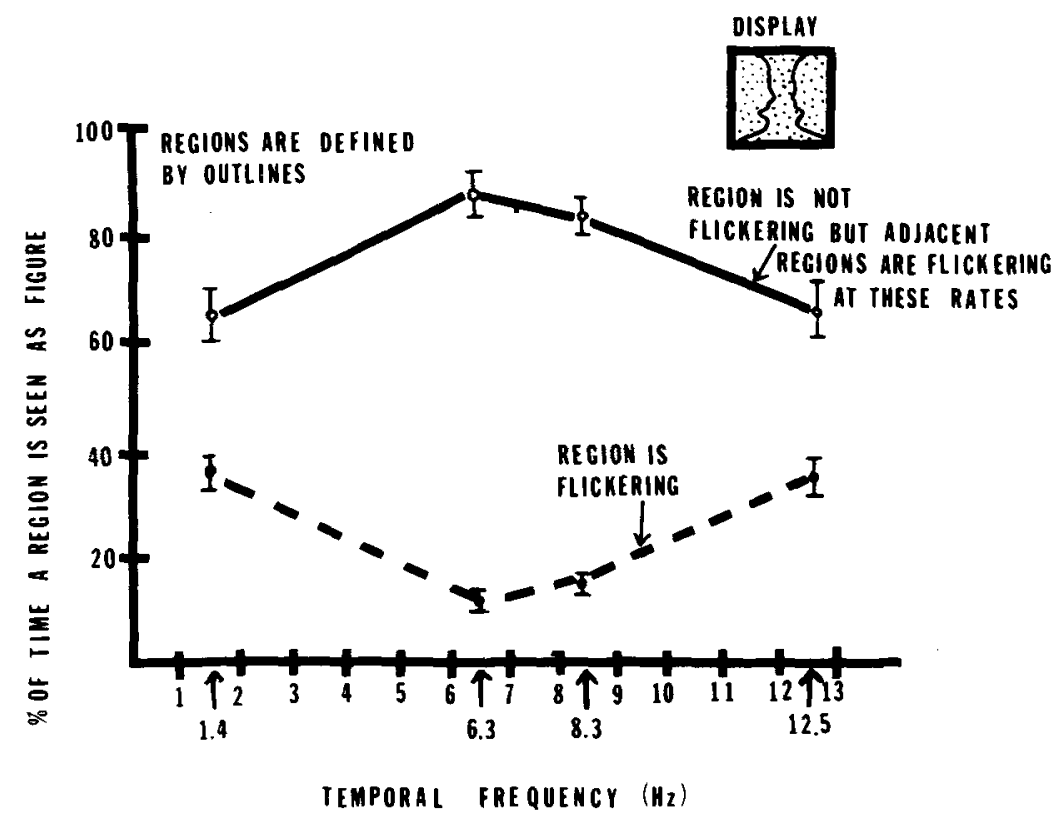

Figure 3. Results of Experiment 1A. The percentage of time a region was seen as figure is plotted as a function of temporal frequency. Data points are presented with their standard errors. 
Table 1

Amount of Perceived Depth and Percentage of Time the Flickering Regions Were Seen as Ground at the Four Temporal Frequencies in Experiment 1A

\begin{tabular}{ccc}
$\begin{array}{c}\text { Frequency } \\
(\mathrm{Hz})\end{array}$ & $\begin{array}{c}\text { Perceived } \\
\text { Depth }(\mathrm{cm})\end{array}$ & $\begin{array}{c}\text { Time Seen } \\
\text { as Ground }(\%)\end{array}$ \\
\hline 1.4 & 0.14 & 65 \\
6.3 & 2.05 & 86.5 \\
8.3 & 2.55 & 84 \\
12.5 & 0.22 & 65 \\
\hline
\end{tabular}

Since there was no significant difference between data from the condition in which the central region flickered and data from the condition in which the flanking regions flickered, the data were collapsed together. Tests of significance using the $z$-statistic (one-tailed) showed that the amount of perceived depth at each temporal frequency was significantly greater than zero $(p<.0001$ for all the values). For all subjects, perceived depth segregation between the flickering and nonflickering regions increased as the percepts became more anchored.

\section{EXPERIMENT 1B}

In this experiment we examined the effect of flicker on figure-ground organization in the Rubin picture when the regions are not outlined by solid contours. We decided to include displays with and without contours bordering regions, for several reasons. First, the presence of contours may introduce border and brightness effects on flicker. Therefore, we needed a condition in which contours were absent to observe any contour effects. Second, in some preliminary studies we found that since the dots filling the regions are randomly generated every trial, there were some displays in which the regions were not so well defined by the dot texture. This affected the perceptual clarity of the shapes of the regions during flicker. Therefore, we needed a condition in which the shapes of regions were defined by contours so that the effects of flicker on the assignment of figure and ground were not affected by difficulty in recognition of the regions' shapes. Together the two conditions (with and without contours) were mutual controls of any extraneous factors that may have intruded into our measurement of the effects of flicker on figure-ground perception.

\section{Method}

Subjects. Twenty new subjects from the undergraduate subject pool participated in the experiment. All had 20/20 vision.

Stimuli and Apparatus. The stimuli and apparatus were the same as those of Experiment 1A, except that the regions of the Rubin picture were not defined by contours. Thus, when flicker was absent, the display was a field of random dots. Flickering the dots in the flanking or central regions caused the areas to segregate into the three segments of the Rubin picture.

Procedure. The procedure was the same as that of Experiment 1A. The subjects were tested again for their perceptual preference to see particular areas as figures or grounds with the display in which the outlines were present.

\section{Results}

The results were similar to those of Experiment $1 \mathrm{~A}$. Subjects did not exhibit any pronounced preference to see any particular segment as figure when flicker was absent. Neither goblet nor faces were perceived more than $60 \%$ of the time.

Again, flicker was effective in inducing ground as a dominant percept and the flickering regions were seen as lying behind the static regions. Flicker was most effective in anchoring a region as ground at 6.3 and $8.3 \mathrm{~Hz}$. The effect of flicker-induced ground diminished as temporal frequency increased or decreased. These results are shown in Figure 4. Since there were no significant differences between data from the condition in which the center flickered and data from the condition in which the flanks flickered, the data were collapsed together. A one-way ANOVA (repeated measures) was performed on the response time in which the flickering region was perceived as ground at four temporal frequencies $(1.4,6.3,8.3$, and $12.5 \mathrm{~Hz})$. The main effect was significant $[F(3,57)=$ $4.67, p<.01$ ]. A post hoc comparison between levels was also performed to determine the contribution of each of the four temporal frequencies. Means for 6.3 and $8.3 \mathrm{~Hz}$ were significantly different from those of the other temporal frequencies. No significant differences were found between 6.3 and $8.3 \mathrm{~Hz}$ or between 1.4 and $12.5 \mathrm{~Hz}$.

The effect of flicker-induced depth between the flickering and nonflickering regions was similar to that found in Experiment 1A. No subject perceived the flickering areas to be in front of the nonflickering areas (binomial, $p<.001$ ). All subjects perceived the flickering and nonflickering dots to be segregated into definite perceptual regions regardless of the amount of depth segregation perceived. Table 2 shows the amount of perceived depth and the percentage of time the flickering regions were seen as backgrounds at the four flicker rates. There was again no significant difference between data from the condition in which the central region flickered and data from the condition in which the flanking regions flickered. Tests of significance using the $z$-statistic (one-tailed) showed that the amount of perceived depth at each temporal frequency was significantly greater than zero $(p<.0001$ for all the values). For all subjects, perceived depth segregation between the flickering and nonflickering regions increased as the percepts became more anchored.

\section{EXPERIMENT 2A}

In this experiment we examined the effect of flicker on figure-ground organization in another reversible picture. We wanted to know how the results from the Rubin reversible picture would generalize to other ambiguous figures.

\section{Method}

Subjects. Twenty new naive observers from the undergraduate pool participated in the experiment. All had 20/20 vision. 


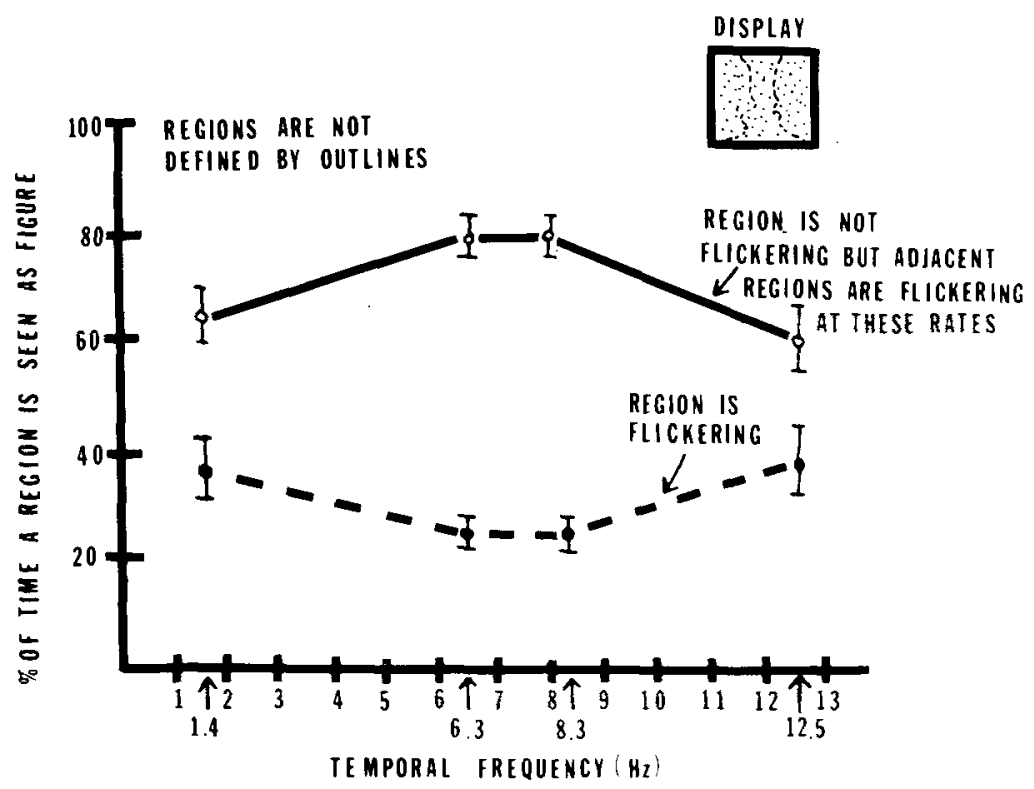

Figure 4. Results of Experiment 1B. The percentage of time a region was seen as figure is plotted as a function of temporal frequency. Data points are presented with their standard errors.

Stimuli and Apparatus. The display used is shown in Figure 5. This picture may be seen as a diagonal band lying on top of a square or as two triangles lying on top of a square. Each figural percept renders the other areas as background. As with the Rubin picture, the display was filled with random dots and the regions were defined by solid contours. The display covered an area $3.2^{\circ} \times 3.2^{\circ}$. Area size and dot density in the three regions were matched as closely as possible.

Procedure. The procedure was in general the same as that of Experiment $1 \mathrm{~A}$.

\section{Results}

The results are similar to those for the Rubin picture. Subjects did not exhibit any pronounced preference for seeing any particular segment as figure when none of the areas flickered. Neither the diagonal band nor the triangles were seen as figure more than $54 \%$ of the time.

As with the Rubin picture, the flickering regions, whether they were the diagonal band in the center or the two triangles, were seen predominantly as backgrounds, while the static regions were seen predominantly as figures. Again, depth segregation between the flickering and nonflickering areas was seen. These visual impressions are illustrated in Figure 6.

As with the Rubin picture, the most pronounced effect of flicker on anchoring a region as ground occurred at 6.3 and $8.3 \mathrm{~Hz}$. The flicker-induced ground effect diminished as temporal frequency increased or decreased. This shows that the temporal frequency effect of figureground perception is generalizable to a display configuration other than the one in which it was originally discovered. Figure 7 shows the results of this experiment. Data from the condition in which the central region flickered and data from the condition in which the two flank- ing regions flickered were collapsed because no significant differences were observed between the two conditions. A one-way ANOVA (repeated measures) was performed on the response time in which the flickering region was perceived as ground at four temporal frequencies $(1.4,6.3,8.3$, and $12.5 \mathrm{~Hz})$. The main effect was significant $[F(3,57)=5.82, p<.005]$. A post hoc comparison between levels was also performed to determine the contribution of each of the four flicker rates to flickerinduced ground. Means for 6.3 and $8.3 \mathrm{~Hz}$ were significantly different from those for the other temporal frequencies. No significant differences were found between 6.3 and $8.3 \mathrm{~Hz}$ or between 1.4 and $12.5 \mathrm{~Hz}$.

Depth separation between the flickering backgrounds and the nonflickering figures was also perceived. The effect was greatest at 6.3 and $8.3 \mathrm{~Hz}$. No subject perceived the flickering regions to be in front of the nonflickering regions for any of the temporal frequencies (binomial, $p<.001$ ). All subjects perceived the flickering and nonflickering dots as being segregated into definite areas, regardless of the amount of depth segregation.

Table 3 shows the amount of depth perceived and the percentage of time the flickering regions were seen as

Table 2

Amount of Perceived Deptb and Percentage of Time the

Flickering Regions Were Seen as Ground at the Four Temporal Frequencies in Experiment 1B

\begin{tabular}{ccc}
\hline $\begin{array}{c}\text { Frequency } \\
(\mathrm{Hz})\end{array}$ & $\begin{array}{c}\text { Perceived } \\
\text { Depth }(\mathrm{cm})\end{array}$ & $\begin{array}{c}\text { Time Seen } \\
\text { as Ground }(\%)\end{array}$ \\
\hline 1.4 & 0.14 & 63 \\
6.3 & 2.4 & 74.5 \\
8.3 & 3.25 & 74.5 \\
12.5 & 0.19 & 61.5 \\
\hline
\end{tabular}




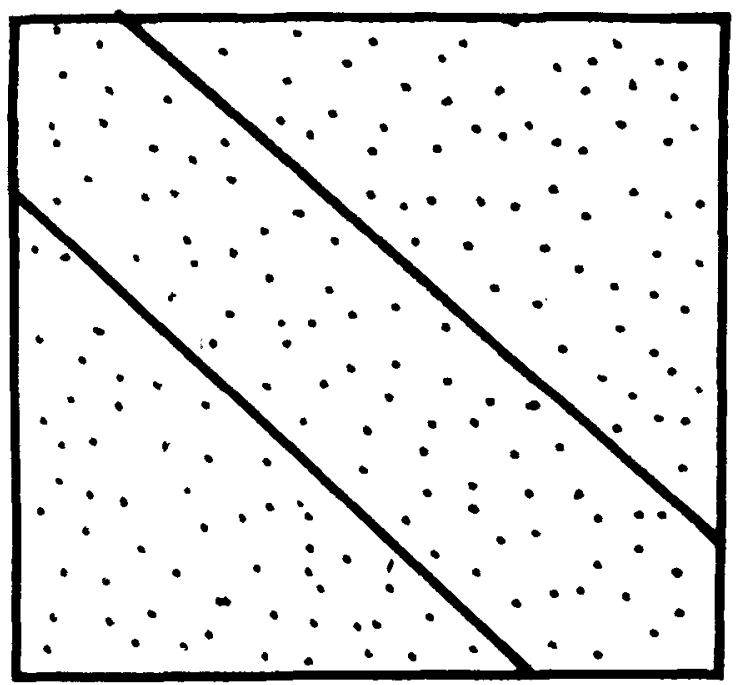

Figure 5. A reversible picture that could be seen as a diagonal band or as two triangles. This display was used in Experiments $2 A$ and $2 \mathrm{~B}$. The three regions of the figure were defined by solid contours in Experiment 2A but not in Experiment 2B.

ground at the four temporal frequencies. Data from the condition in which the central region flickered and data from the condition in which the flanking regions flickered were collapsed, because no pronounced difference was observed between the two conditions.

Tests of significance using the $z$-statistic ( one-tailed) showed that the amount of perceived depth in each temporal frequency was significantly greater than zero ( $p<.0001$ for all values). For all subjects, perceived amount of depth segregation between the flickering and nonflickering regions increased as the percepts became more anchored.

\section{EXPERIMENT 2B}

This experiment was designed to examine the effect of flicker on figure-ground perception when the regions of the ambiguous picture used in Experiment $2 \mathrm{~A}$ were not defined by solid contours. The rationale for including displays with and without contours defining the regions was given in Experiment 1B.

\section{Method}

Subjects. Twenty new naive subjects from the undergraduate subject pool participated. All had 20/20 vision.

Stimuli and Apparatus. These were similar to those in Experiment $2 \mathrm{~A}$, except that in the display no solid contours outlined the boundaries between the triangles and the diagonal band. In the absence of flicker, the display was a field of random dots. Flickering segregated the picture into the three regions shown in Figure 5.

Procedure. The procedure was similar to that of Experiment 2A. Subjects' perceptual biases to organize particular regions as figure or as ground were tested using the picture with the solid contours.

\section{Results}

The results resembled those of the other experiments. Subjects showed no pronounced preference for seeing either triangles or the diagonal band when flicker was absent. Neither the diagonal band nor the two triangles were seen as figure more than $58 \%$ of the time.

As in the other experiments, the flickering regions were organized predominantly as backgrounds and the nonflickering regions as figures, regardless of whether they were the flanking areas or the central area. Again, the most pronounced effects of flicker in anchoring a region as ground were at 6.3 and $8.3 \mathrm{~Hz}$. Figure 8 shows the results of this experiment. Data from the condition in which the triangles flickered and data from the condition in which the diagonal band flickered were collapsed together, because no pronounced differences were observed between the two conditions. A one-way ANOVA (repeated measures) analysis was performed on the response time in which the flickering region was perceived as ground at four temporal frequencies $(1.4,6.3,8.3$, and $12.5 \mathrm{~Hz})$. The main effect was significant $[F(3,57)=4.72$, $p<.01]$. A post hoc comparison between levels was also performed to determine the contribution of each of the four temporal frequencies. Means for $6.3 \mathrm{and} 8.3 \mathrm{~Hz}$ were significantly different from those for the other flicker rates. No significant differences existed between 6.3 and $8.3 \mathrm{~Hz}$ or between 1.4 and $12.5 \mathrm{~Hz}$.

Flickering also produced depth segregation between the flickering and nonflickering areas at all temporal frequencies used in this experiment. No subject perceived the flickering areas to be in front of the nonflickering areas (binomial, $p<.001$ ). All observers perceived the flickering and nonflickering dots to be segregated into definite regions, regardless of the amount of depth seen. Table 4 shows the amount of depth segregation perceived and the percentage of time the flickering regions were seen as ground at the four temporal frequencies used in the ex-
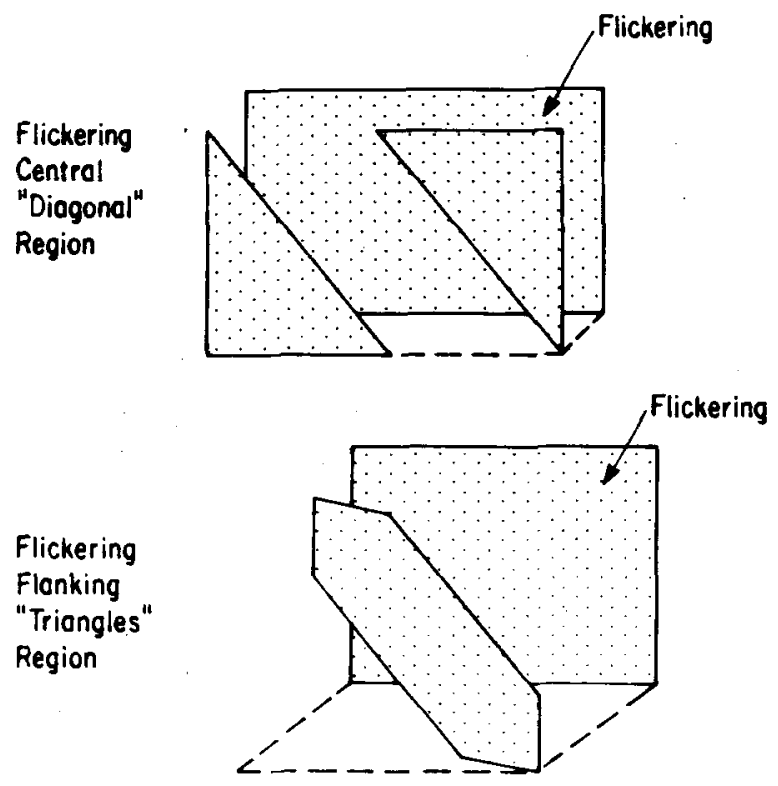

Figure 6. Visual impression of the diagonal/triangles reversible picture when the central regions flickered and when the flanking regions flickered. 


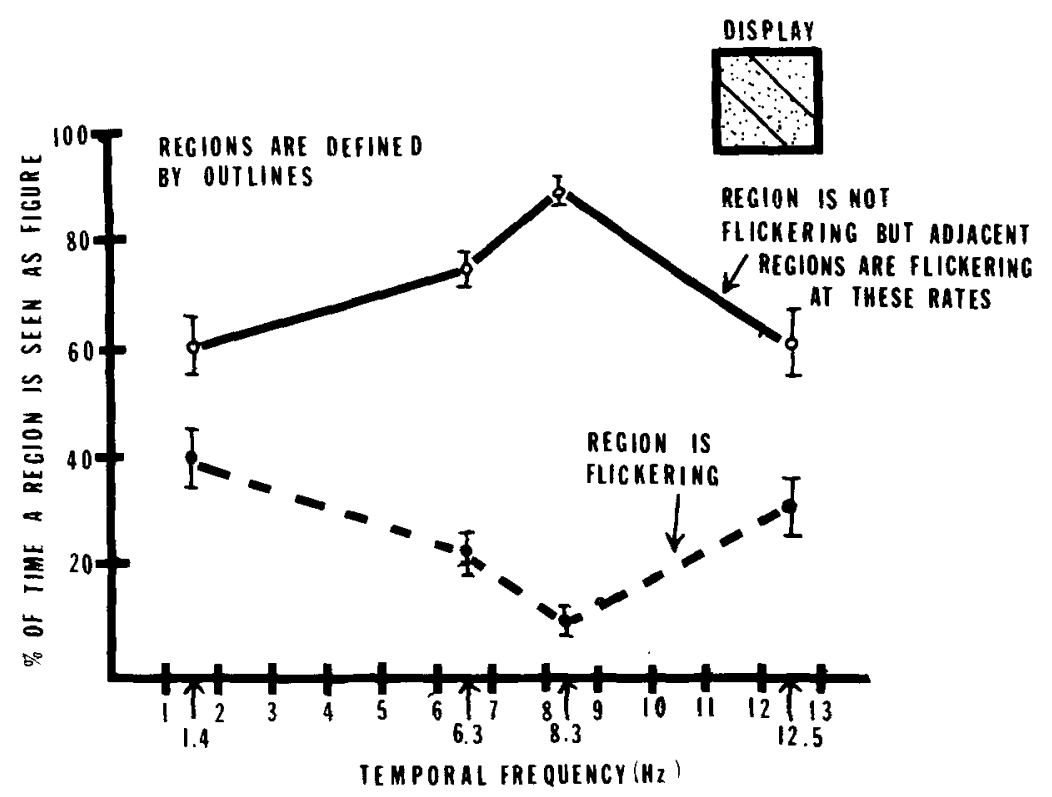

Figure 7. Results of Experiment 2A. The percentage of time a region was seen as figure is plotted as a function of temporal frequency. Data points are presented with their standard errors.

periment. Tests of significance using the $z$-statistic (onetailed) showed that the amount of perceived depth at each temporal frequency was significantly greater than zero ( $p<.0001$ for all values). For all subjects, perceived depth segregation between the flickering and nonflickering regions increased as the percepts became more anchored.

\section{DISCUSSION}

Flickering regions of the visual field were perceived predominantly as backgrounds and nonflickering areas were perceived primarily as figures. This effect of flickerinduced ground was greatest at 6.3 and $8.3 \mathrm{~Hz}$. Although frequencies of 1.4 and $12.5 \mathrm{~Hz}$ produced vivid segregation of the flickering and nonflickering regions, no effect of anchoring of a particular region as figure or as ground was observed. Since the average luminance of the flickering and nonflickering fields was kept equal, figureground perception could not have been due to luminance differences. Perceived brightness, however, has been observed to be associated with figure-ground organization. Figure regions were perceived as brighter (Festinger

Table 3

Amount of Perceived Depth and Percentage of Time the Flickering Regions Were Seen as Ground at the Four Temporal Frequencies in Experiment 2A

\begin{tabular}{ccc}
$\begin{array}{c}\text { Frequency } \\
(\mathrm{Hz})\end{array}$ & $\begin{array}{c}\text { Perceived } \\
\text { Depth }(\mathrm{cm})\end{array}$ & $\begin{array}{c}\text { Time Seen } \\
\text { as Ground }(\%)\end{array}$ \\
\hline 1.4 & 0.16 & 60 \\
6.3 & 2.1 & 76 \\
8.3 & 3.4 & 88 \\
12.5 & 0.18 & 68 \\
\hline
\end{tabular}

et al., 1970), and, other factors being constant, brighter areas were more likely to be seen as figure (Graham, 1929; Oyama, 1960; Oyama \& Sasamoto, 1957). Can perceived brightness differences between the flickering and nonflickering regions account for our findings? We think not. In our displays, although the average physical luminances of the flickering and nonflickering regions were kept equal, regardless of whether the flickering regions were reported as brighter, dimmer, or the same as the nonflickering area, the flickering areas were predominantly seen as backgrounds. Examination of our subjects' reports of perceived brightness of the regions of the display showed that over $90 \%$ of the subjects (from all four experiments) reported that the flickering areas appeared brighter at all of the flicker rates. Moreover, only at 6.3 and $8.3 \mathrm{~Hz}$ were the effects of flicker most pronounced on anchoring regions as ground. This temporal tuning resembles the tuning of visual pathways that are maximally sensitive to high temporal and low spatial frequencies (Burbeck \& Kelly, 1981; Legge, 1978; Robson, 1966; Tolhurst, 1975). Therefore, the effects of flicker on figure-ground perception in the present experiments cannot be attributed to perceived brightness. Rather, they suggest a relationship between figure-ground perception and the temporal frequency response of the visual system.

Flickering regions were also perceived to lie in a depth plane behind that of the nonflickering regions. This finding is consistent with our earlier findings (Wong \& Weisstein, 1984a) using alternating patches of flickering and nonflickering random dots. The amount of depth separation between the two regions increased as the regions became more anchored as figure and ground. That figureground segregation is accompanied by the perception that 


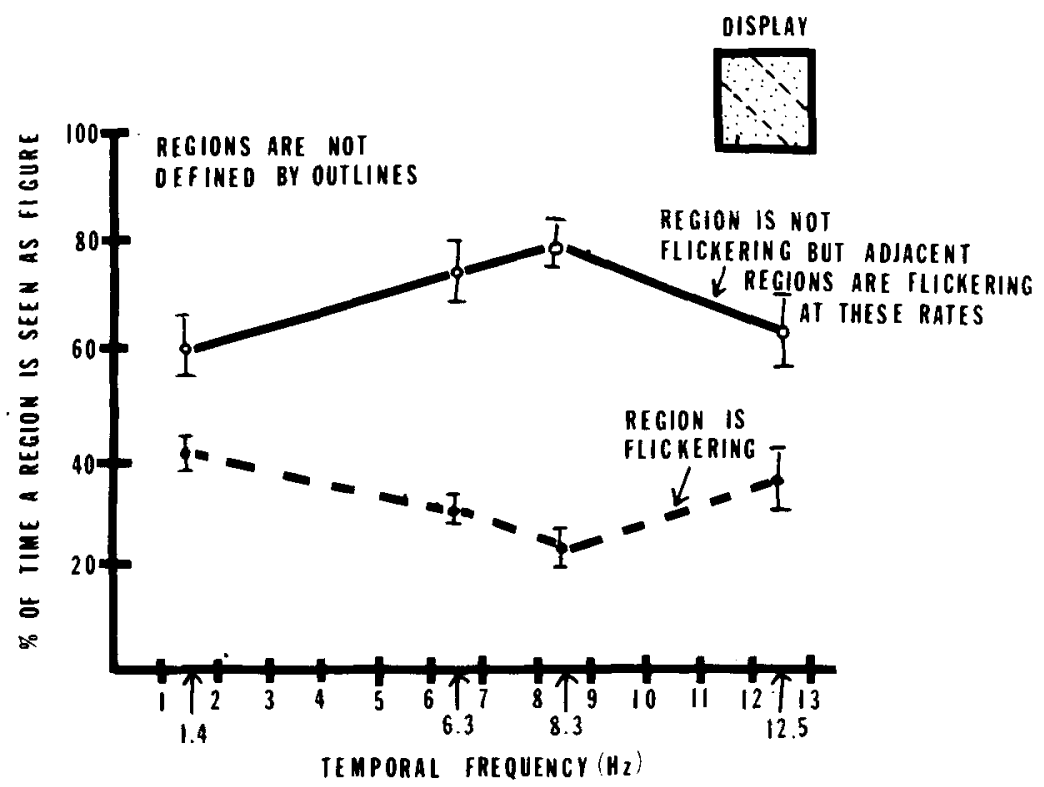

Figure 8. Results of Experiment 2B. The percentage of time a region was seen as figure is plotted as a function of temporal frequency. Data points are presented with their standard errors.

the figure lies on a depth plane in front of the background has been observed by others (Coren, 1969; Julesz, 1971; Koffka, 1935). Our findings suggest that figure-ground perception, depth segregation, and visual pathways sensitive to high temporal frequencies are closely related. Since flicker anchors figure and ground and, concurrently, induces a depth separation between them, the findings reported here cannot specify whether flicker "causes" anchoring of figure and ground, which in turn leads to depth segregation, or whether flicker "causes" depth separation, which determines figure-ground organization. We are currently conducting research in our laboratory to address this issue.

It has been demonstrated that temporal changes (e.g., motion) can be powerful determinants of perceptual segregation of the visual field (Anstis, 1970; Baker \& Braddick, 1982; Bell \& Lappin, 1973; Braddick, 1974; Chang \& Julesz, 1983; Nakayama, 1981; Regan, 1986; Regan \& Beverley, 1984; Reichardt \& Poggio, 1983). Can our effect of flicker-induced ground be regarded as a phenomenon related to motion-based segregation? We think that at present it is premature to conclude that there is a relationship between motion-based segregation of the

Table 4

Amount of Perceived Depth and Percentage of Time the Flickering Regions Were Seen as Ground at the Four Temporal Frequencies in Experiment 2B

\begin{tabular}{ccc}
\hline $\begin{array}{c}\text { Frequency } \\
(\mathrm{Hz})\end{array}$ & $\begin{array}{c}\text { Perceived } \\
\text { Depth (cm) }\end{array}$ & $\begin{array}{c}\text { Time Seen } \\
\text { as Ground (\%) }\end{array}$ \\
\hline 1.4 & 0.1 & 60 \\
6.3 & 1.6 & 71 \\
8.3 & 2.9 & 77 \\
12.5 & 0.1 & 65 \\
\hline
\end{tabular}

visual field and the results of our experiments on flicker and figure-ground perception.

First, motion-based segregation has been observed under threshold conditions in which the interest has been in the minimal displacement, velocity, and spatial area needed for one region to be segregated from another. The role of motion per se in determining which region would be seen as figure or as ground has not been addressed. The experiments reported here were concerned with suprathreshold conditions in which segregation was not an issue. Rather, our interest was, given that the visual system is able to segregate objects, what kinds of stimulus conditions and response characteristics of the visual system determine which region is seen as figure or as ground. Our experiments (Wong \& Weisstein, 1984a, 1985 , and the present experiments) have shown that there are circumstances in which two regions are segregated but no one region is perceived predominantly as figure or as ground. For example, a field flickering at $12.5 \mathrm{~Hz}$ was segregated from an adjacent nonflickering area, but neither field was perceived predominantly as figure. Thus, segregation does not necessarily imply perceptual anchoring of figure and ground, although the anchoring of figure and ground does imply segregation. It is therefore difficult to draw conclusions about the relationship between our results on flicker-induced ground and motion-based segregation, because the two types of studies seem to be examining different phenomena.

Second, there are some differences with regard to the visual impression of depth segregation in our flickering displays and in the displays using moving random dots (Baker \& Braddick, 1982; Nakayama, 1981; Regan, 1986). In our experiments the flickering regions were al- 
ways seen to lie behind the nonflickering areas. With displays of moving dots, however, it has been reported that patches of faster-moving dots appeared to be in front of areas of slower-moving dots, whereas regions of stationary dots appeared to be in front of regions of moving dots (Julesz, 1971). Because there has been no systematic study of how the speed of the moving dots affects the anchoring of figure and ground and their depth relationship, we cannot make any conclusive statements about the flickerinduced ground and motion-induced figure-ground segregation.

In conclusion, our studies suggest that figure-ground perception, depth segregation, and temporal frequency are closely related. Whether flicker-based and motion-based figure-ground perception can be regarded as related phenomena cannot be determined from these experiments. We hope that further studies will clarify the relationship of these two kinds of temporal changes to the perception of figure and ground.

\section{REFERENCES}

ANSTIS, S. (1970). Phi movement as a subtraction process. Vision Research, 10, 1411-1430.

BAHNSEN, P. (1928). Eine Untersuchung über Symmetrie und Asymmetrie bei visuellen Wahrnehmungen. Zeitschrift für Psychologie, 108, 355-361.

BAKER, C. L., JR., \& Braddick, O. J. (1982). Does segregation of differently moving areas depend on relative or absolute motion? Vision Research, 22, 851-856.

Bell, H. H., \& LAPPIN, J. S. (1973). Sufficient conditions for the discrimination of motion. Perception \& Psychophysics, 14, 45-50.

BRADDICK, O. J. (1974). A short-range process in apparent motion. $\mathrm{Vi}$ sion Research, 14, 519-527.

Burbeck, C., \& Kelly, D. H. (1981). Contrast gain measurements and the transient/sustained dichotomy. Journal of the Optical Society of America, 71, 1335-1342.

Chang, J. J., \&ulesz, B. (1983). Displacement limits, directional anisotrophy, and direction versus form discrimination in random dot cinematograms. Vision Research, 23, 639-646.

COREN, S. (1969). Brightness contrast as a function of figure-ground relations. Journal of Experimental Psychology, 80. 517-524.

Festinger, L., Coren, S., \& Rivers, G. (1970). The effects of attention on brightness contrast and assimilation. American Journal of Psychology, 83, 189-207.

Frank, H. (1923). Über die Beeinflussung von Nachbilden durch die Gestalteigenschaften der Projecktionfläche. Psychologische Forschung, 4, 22-41.

Frost, B. J., \& NakAyama, K. (1983). Single neurons code opposing motion independent of direction. Science, 220, 744-745.

GOLDHAMmER, H. (1934). The influence of area, position, and brightness in the visual perception of a reversible configuration. American Journal of Psychology, 46, 189-206.
Graham, C. H. (1929). Area, color, and brightness difference in a reversible configuration. Journal of General Psychology, 2, 470-481.

HARRower, M. R. (1936). Some factors determining figure-ground articulaton. British Journal of Psychology, 26, 407-424.

JULESZ, B. (1971). The foundations of cyclopean perception. Chicago: University of Chicago Press.

KoffKa, K. (1935). Principles of gestalt psychology. New York: Harcourt, Brace.

KüNNAPAS, T. M. (1957). Experiments on figure dominance. Journal of Experimental Psychology, 53. 31-39.

LEGGE, G. E. (1978). Sustained and transient mechanisms in human vision: Temporal and spatial properties. Vision Research, 18, 69-81.

NaKayama, K. (1981). Differential motion hyperacuity under conditions of common image motion. Vision Research, 21, 1475-1482.

Oyama, T. (1960). Figure-ground dominance as a function of sector angle, brightness, hue, and orientation. Joumal of Experimental Psychology, 60, 299-305.

OYama, T., Sasamoto, S. (1957). Experimental studies of figureground reversal: II. The effects of brightness, brightness gradient, and area in the tachistoscopic presentation. Japanese Journal of Psychology, 28 (Japanese text 18-27; English summary 64-65).

OYAMA, T., \& TORRI, S. (1955). Experimental studies of figure-ground reversal: I. The effects of area, voluntary control, and prolonged observation in continuous presentation. Japanese Journal of Psychology, 26 (Japanese text, 178-188; English summary, 217-218).

RegaN, D. (1986). Visual processing of relative motion. Vision Research, 26, 127-145.

REgAN, D., \& BEVERLEY, K. I. (1984). Figure-ground segregation by motion contrast. Journal of the Optical Society of America $A, 1$, 433-442.

ReichardT, W., \& Poggio, T. (1983). Figure-ground discrimination by relative movement in the visual system of the fly. Biological Cybernetics, 46, 81-100.

Rosson, J. G. (1966). Spatial and temporal contrast sensitivity functions of the visual system. Journal of the Optical Society of America, 56, 1141-1142.

Rubin, E. (1958). Figure and ground. In D. C. Beardslee \& M. Wertheimer (Eds.), Readings in perception (pp. 194-203). Princeton, NJ: Van Nostrand. (Original work published 1921)

TolHURST, D. J. (1975). Sustained and transient channels in human vision. Vision Research, 15, 1151-1155.

WoNG, E., \& WeISSTEIN, N. (1984a). Flicker induces depth: Spatial and temporal factors in the perceptual segregation of flickering and nonflickering regions in depth. Perception \& Psychophysics, 35, 229-236.

WONG, E., \& WEISSTEIN, N. (1984b, May). Flickering regions of a reversible figure are seen as backgrounds and nonflickering regions are seen as figures. Paper presented at the Association for Research in Vision and Ophthalmology meeting, Sarasota, FL.

WoNG, E. \& Weisstein, N. (1985). A new visual illusion: Flickering fields are localized in a depth plane behind nonflickering fields. Perception, 14, 13-17.

(Manuscript received August 26, 1986; revision accepted for publication January 27,1987 .) 